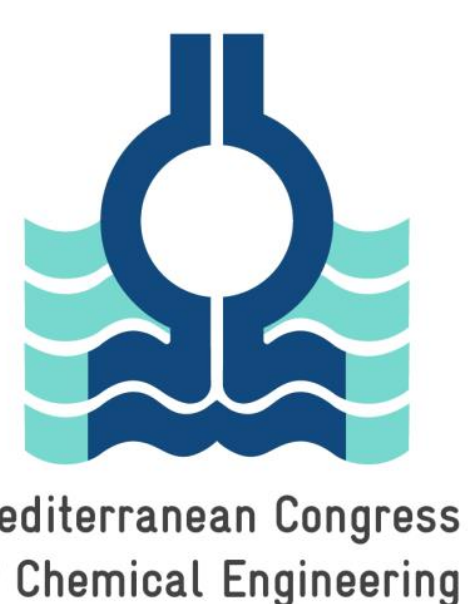

\title{
Preliminary optimization of the environmental performance of PHA downstream processing
}

Mateo Saavedra del Oso, Miguel Mauricio-Iglesias and Almudena Hospido Group of Environmental Biotechnnology Universidade de Santiago de Compostela 
Building blocks for a sustainable bioplastic value chain

$100 \mathrm{Mt}$ of food waste/year

Biobased packaging products
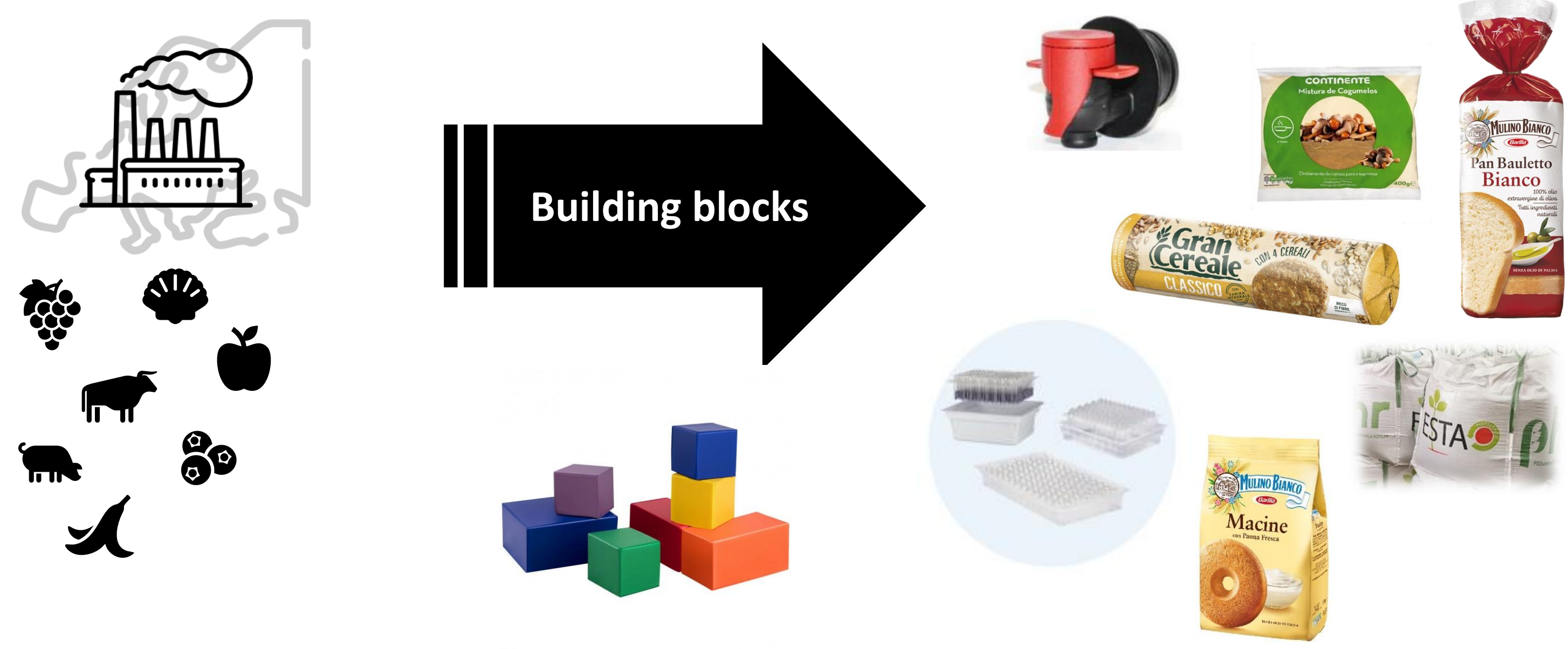


\section{Framework: knowledge integration for efficient decision making}

\section{BIOPLASTIC VALUE CHAIN}

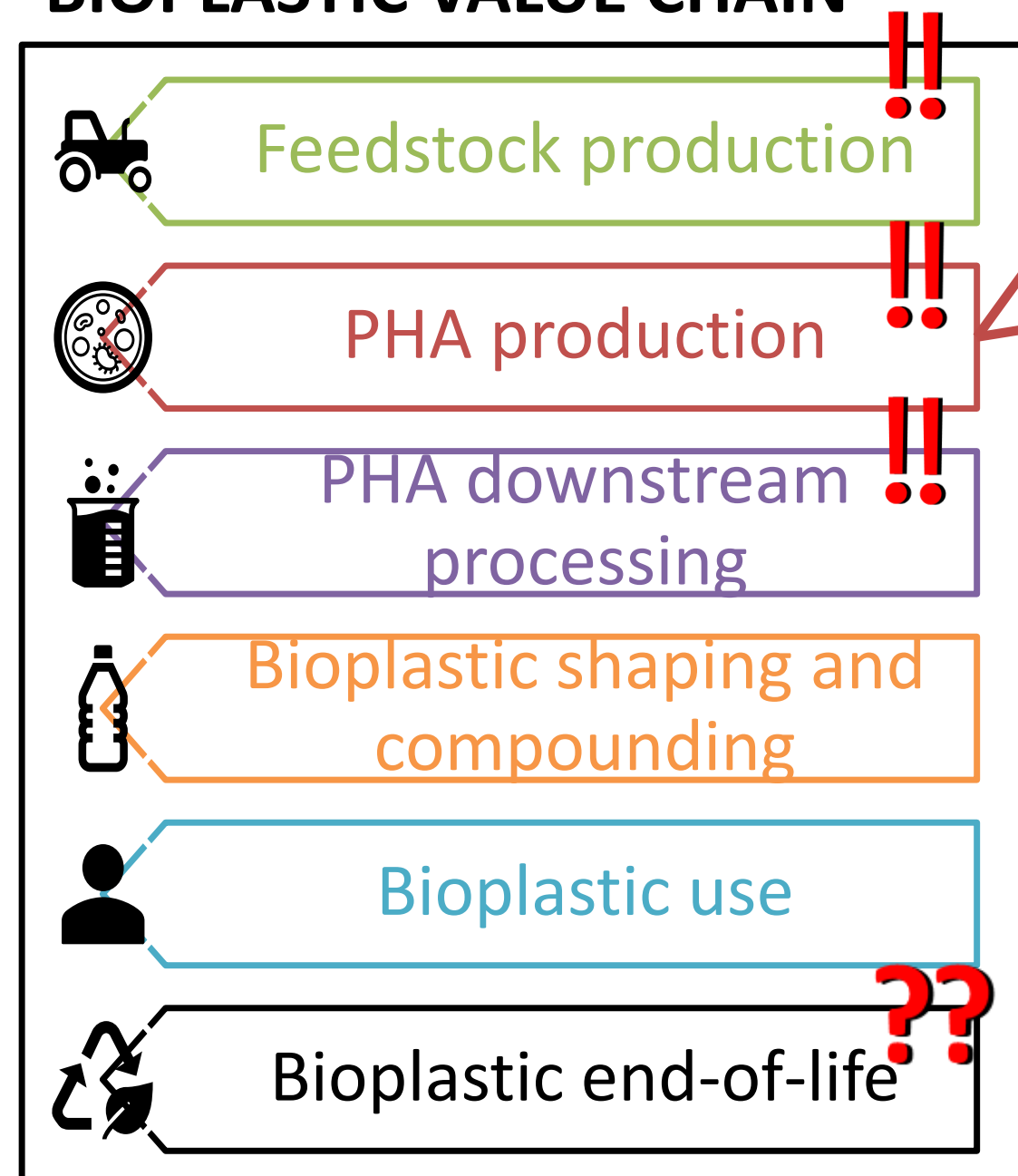

MATHEMATICAL MODELLING

PHA accumulation

VFA production
(2)

Process optimization
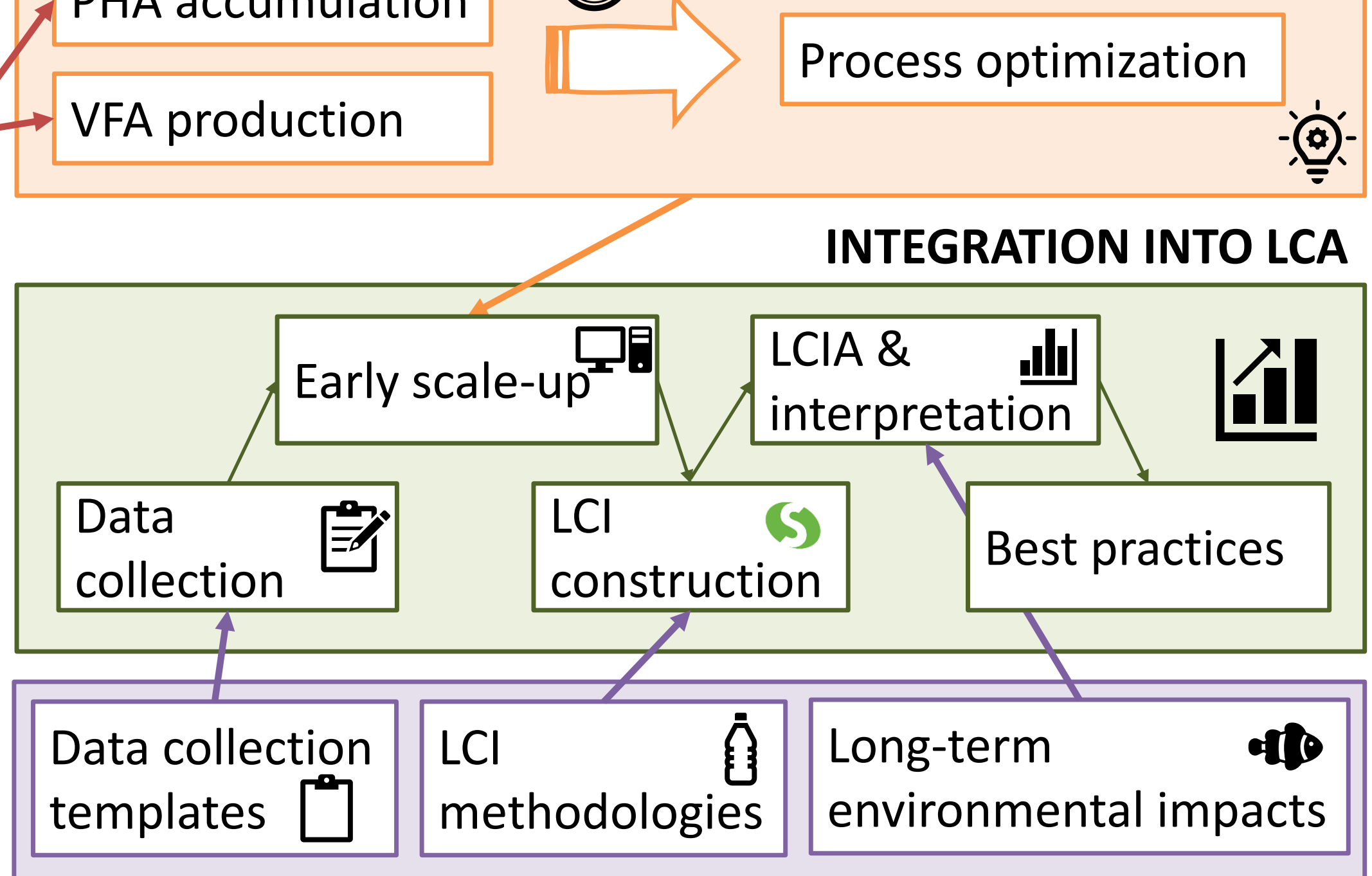


\section{Bioplastic value chain hotspot: PHA downstream processing}
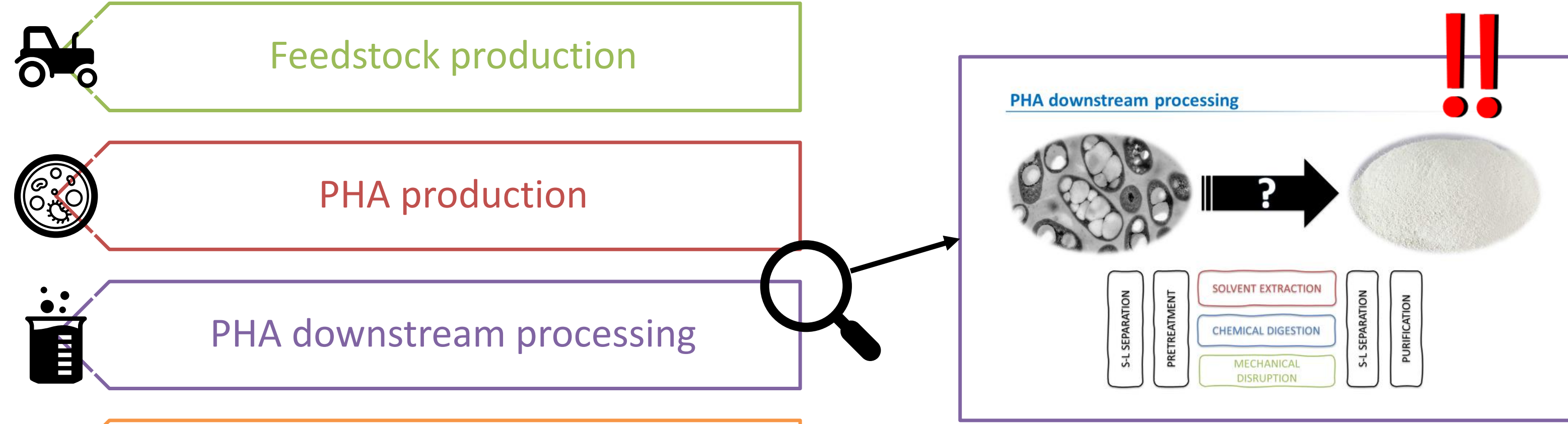

3 Bioplastic shaping and compounding

Bioplastic use

\section{Optimization of the} environmental performance

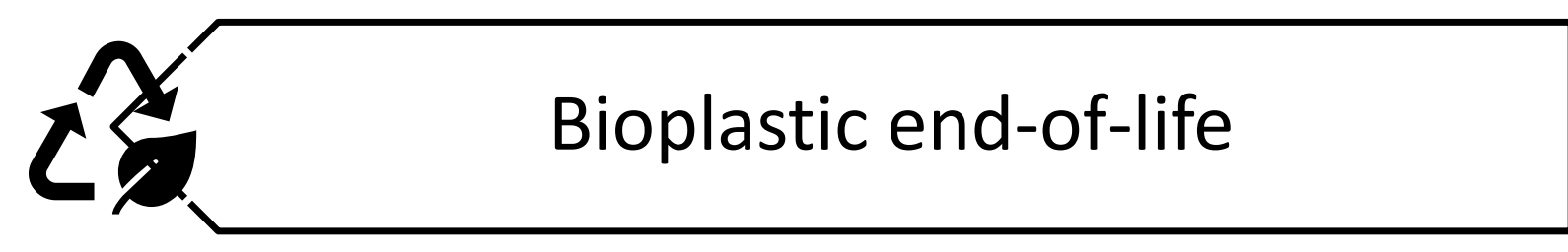




\section{Product requirements and processes selection}

\begin{tabular}{|cccc|}
\hline Quality & Chemical impurities & High molecular weight & Comply EU No 10/2011? \\
\hline High-grade $(\mathrm{H})$ & 0 & & \\
\hline Low-grade (L) & 0 & $O$ & 0 \\
\hline
\end{tabular}

\begin{tabular}{|c|c|c|c|c|c|c|c|c|c|}
\hline $\mathbf{G}$ & Feedstock & Culture & Method & TRL & $\mathbf{G}$ & Feedstock & Culture & Method & TRL \\
\hline H1 & Glucose & Pure & $\begin{array}{l}\text { Acetone } \\
\text { extraction }\end{array}$ & 9 & L1 & Methane & Pure & $\begin{array}{c}\text { Acetone } \\
\text { extraction }\end{array}$ & 4 \\
\hline $\mathrm{H} 2$ & Food waste & Pure & $\begin{array}{c}\mathrm{HPH}+\mathrm{SDS} \\
\text { digestion }\end{array}$ & 9 & \multirow[t]{2}{*}{ L2 } & \multirow{2}{*}{$\begin{array}{c}\text { Canning } \\
\text { wastewater }\end{array}$} & \multirow{2}{*}{$\begin{array}{l}\text { Halophilic } \\
\text { bacteria }\end{array}$} & \multirow{2}{*}{$\begin{array}{c}\text { Osmotic } \\
\text { shock + SDS } \\
\text { digestion }\end{array}$} & \multirow[t]{2}{*}{4} \\
\hline \multirow{2}{*}{ H3 } & \multirow{2}{*}{ Oleic acid } & \multirow{2}{*}{ Pure } & \multirow{2}{*}{$\begin{array}{c}\mathrm{NaOH}+\text { Lysol } \\
\text { digestion }\end{array}$} & \multirow{2}{*}{4} & & & & & \\
\hline & & & & & \multirow{2}{*}{ L3 } & \multirow{2}{*}{ Wastewater } & \multirow{2}{*}{$\begin{array}{l}\text { Mixed } \\
\text { culture }\end{array}$} & \multirow{2}{*}{$\begin{array}{c}\mathrm{NaClO}+\mathrm{SDS} \\
\text { digestion }\end{array}$} & \multirow{2}{*}{4} \\
\hline \multirow{2}{*}{ H4 } & \multirow{2}{*}{$\begin{array}{l}\text { Glucose, } \\
\text { soybean oil }\end{array}$} & \multirow{2}{*}{ Pure } & \multirow{2}{*}{$\begin{array}{c}\text { Ethyl acetate } \\
\text { extraction }\end{array}$} & \multirow{2}{*}{6} & & & & & \\
\hline & & & & & L4 & $\begin{array}{l}\text { Molasses } \\
\text { byproducts }\end{array}$ & Pure & $\begin{array}{c}\text { Fusel alcohols } \\
\text { extraction }\end{array}$ & 8 \\
\hline
\end{tabular}




\section{Scenarios definition}

\section{H1}

(acetone extraction)

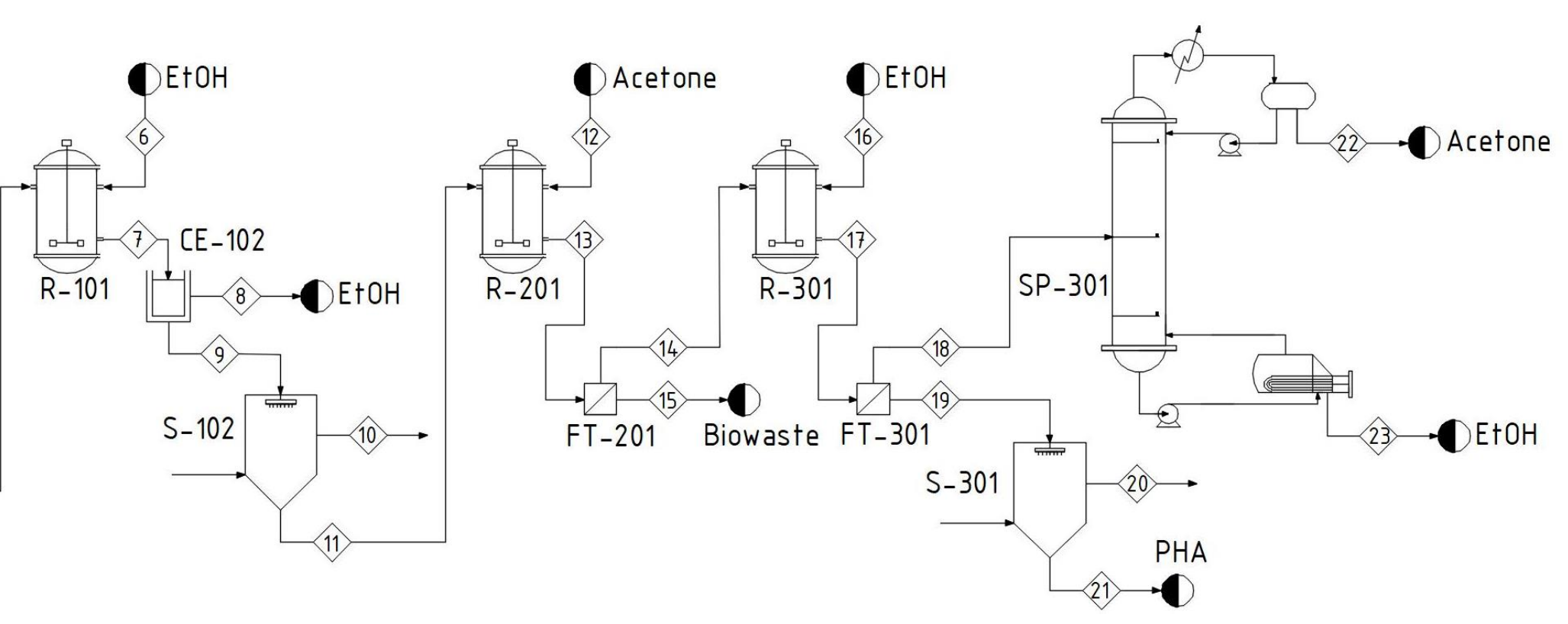

L2

(osmotic shock + SDS digestion)
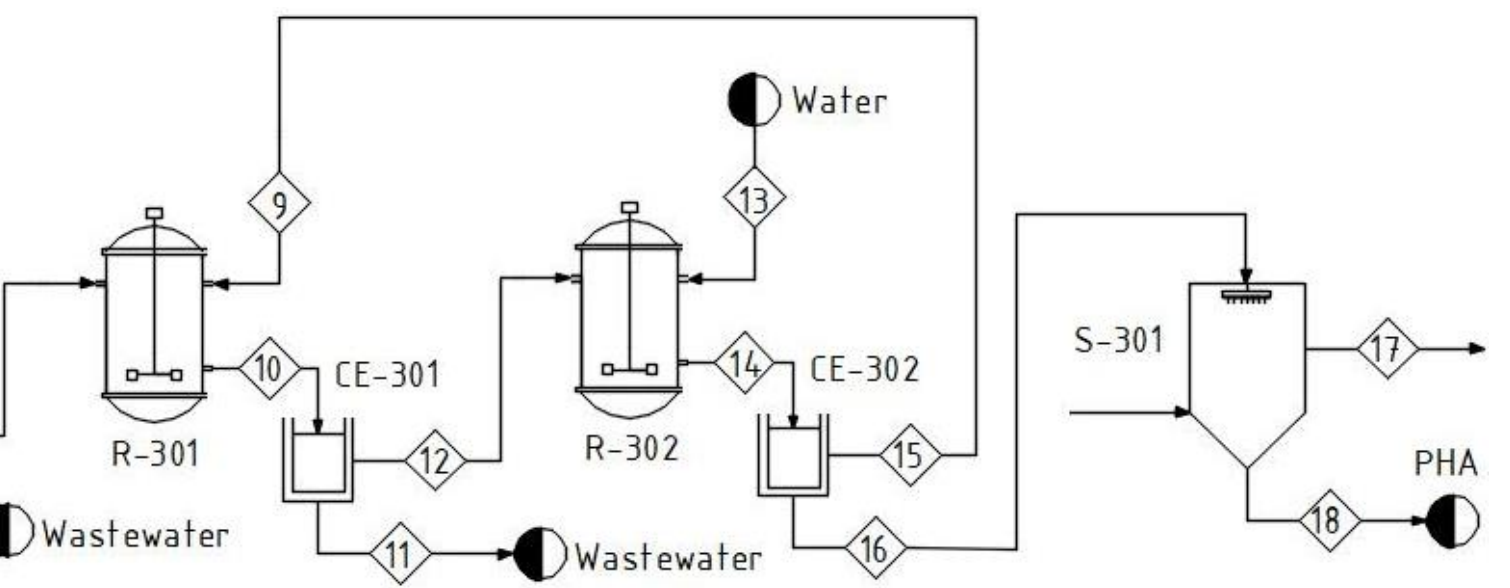

PHA enriched biomass
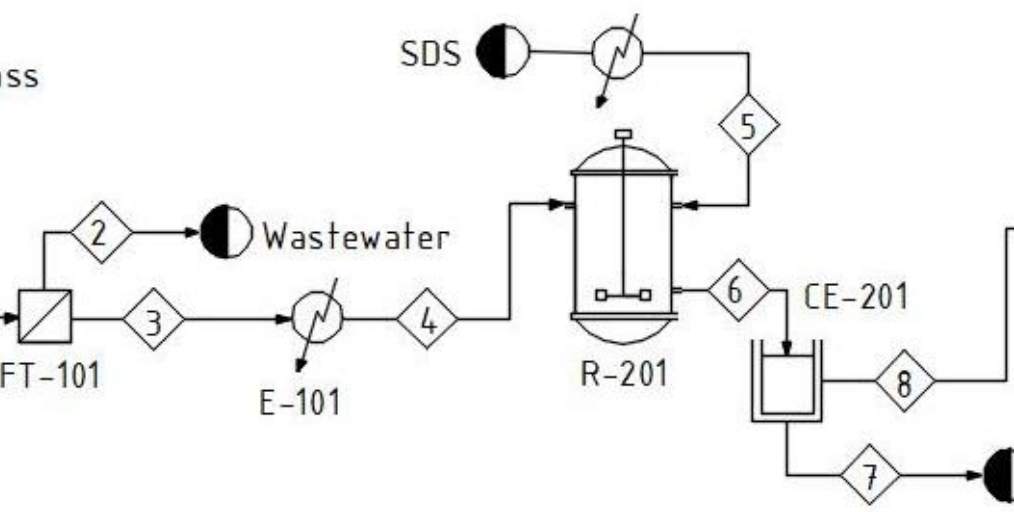

Wastewater

11) $\longrightarrow$ Wastewater 


\section{Goal \& Scope}

SYSTEM FUNCTION: to obtain high-grade or low-grade PHA powder

FUNCTIONAL UNIT: 1 kg high-grade PHA powder or 1 kg low-grade PHA powder

\section{GATE-TO-GATE: from PHA enriched biomass to PHA powder}

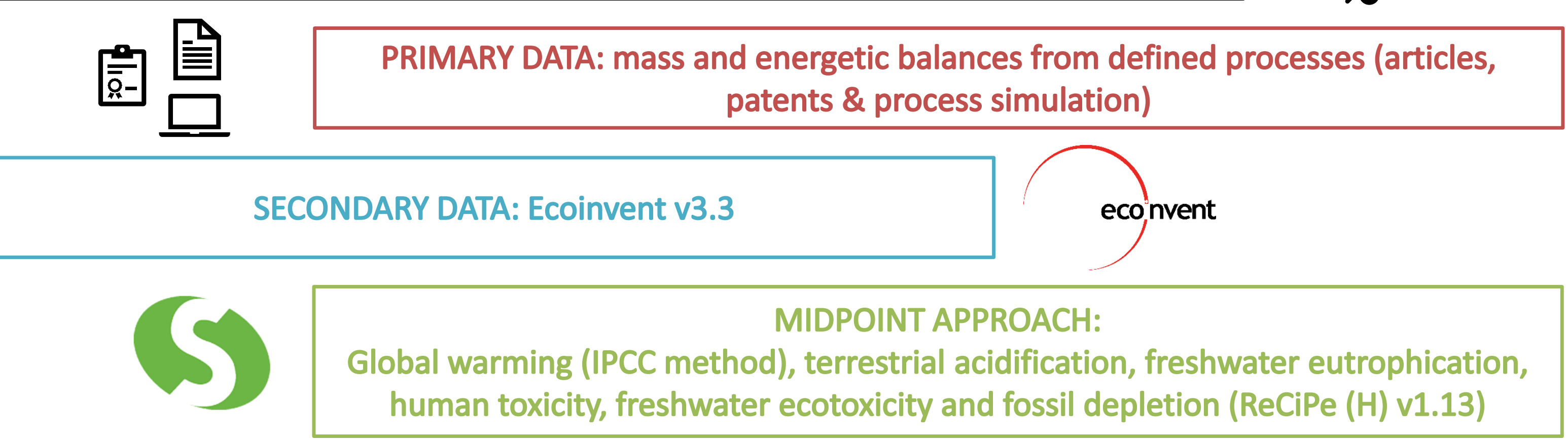




\section{Life cycle impact assessment: 1 kg high-grade PHA}
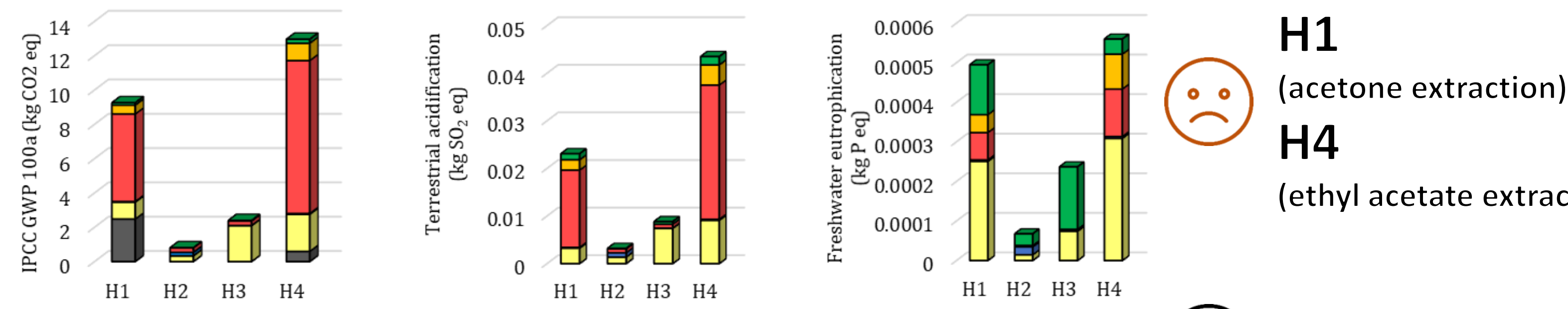

(ethyl acetate extraction)
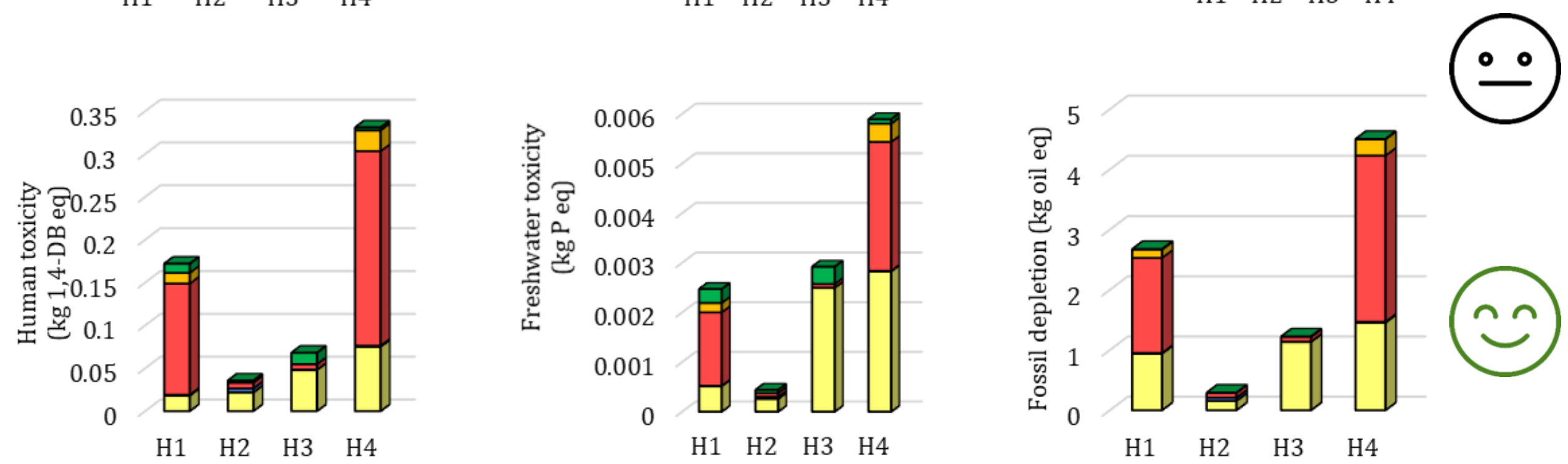

$\mathrm{H3}$

( $\mathrm{NaOH}+$ Lysol digestion)

$\square$ Direct emissions $\square$ Chemicals $\square$ Electricity $\square$ Heat duty $\square$ Cooling duty $\square$ Waste or wastewater treatment 


\section{Life cycle impact assessment: 1 kg low-grade PHA}
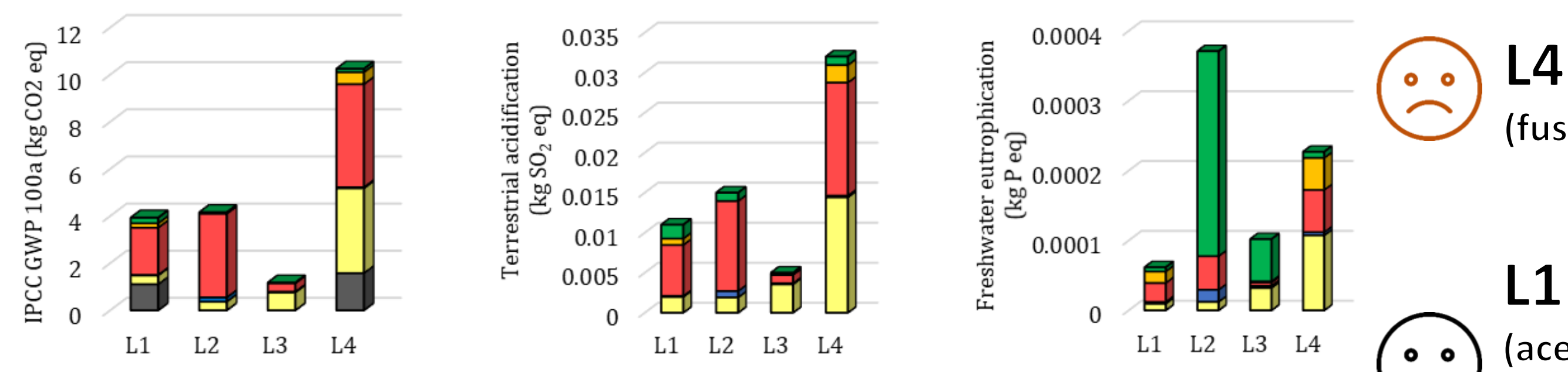

(fusel alcohols extraction)
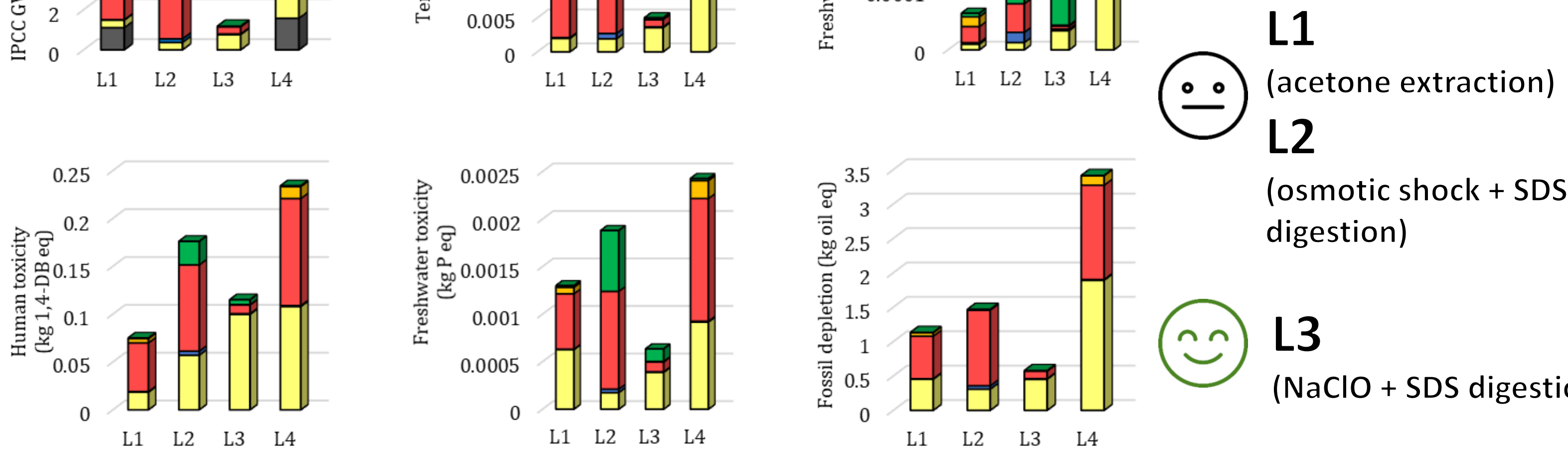

$\square$ Direct emissions $\square$ Chemicals $\square$ Electricity $\square$ Heat duty $\square$ Cooling duty $\square$ Waste or wastewater treatment 


\section{Optimization of the environmental performance}

\begin{tabular}{|c|c|c|c|}
\hline Technology & Hotspot & Scenario assessed & Result \\
\hline \multirow{2}{*}{ Solvent extraction } & \multirow{2}{*}{$\begin{array}{l}\text { Heat consumption in solvent } \\
\text { recovery }\end{array}$} & Oil as heat source & \\
\hline & & Natural gas as heat source & \\
\hline \multirow{2}{*}{ Chemical digestion } & \multirow{2}{*}{ Chemicals consumption } & Chemicals are not recovered & \\
\hline & & Chemical are recovered & \\
\hline \multirow{2}{*}{ Mechanical disruption } & \multirow{2}{*}{$\begin{array}{c}\text { Electricity consumption in } \\
\text { HPH }\end{array}$} & High-carbon electricity mix (Polish) & \\
\hline & & Low-carbon electricity mix (Swedish) & \\
\hline
\end{tabular}

\begin{tabular}{|cccccc|}
\hline \multirow{2}{*}{ Process } & \multirow{2}{*}{ Framework } & Improvement & \multicolumn{3}{c|}{ Environmental impacts reduction } \\
& actions & GWP & Human toxicity & Fossil depletion \\
\hline $\mathbf{L} 2$ & Larger facilities with & Heat & $83 \%$ & $50 \%$ & $73 \%$ \\
\cline { 1 - 2 } & available residual vapor & integration & $12 \%$ & $13 \%$ & $11 \%$ \\
\hline
\end{tabular}




\section{Conclusions}

- Most promising PHA downstream processes were identified and evaluated

- Preliminary insights for the optimization of their environmental performance were provided

- Solvent extraction require high amounts of energy. Heat integration and the utilization so-called green solvents can reduce the environmental impacts

- Chemical digestion shows a better environmental performance when is combined with mechanical disruption or chemicals are recovered

- High pressure homogenisation is the most promising method from a environmental perspective 


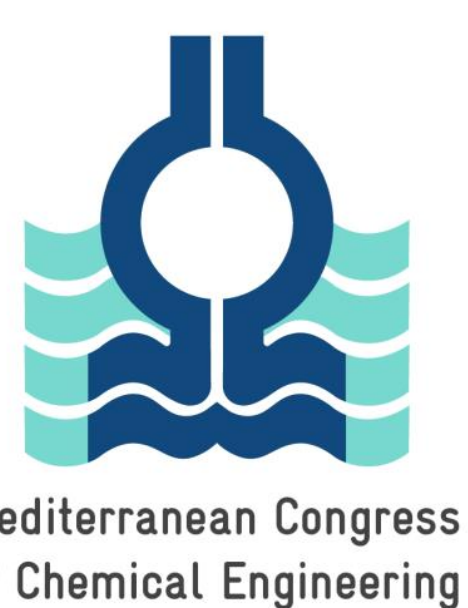

\title{
Preliminary optimization of the environmental performance of PHA downstream processing
}

\author{
msaavedra.deloso@usc.es
}

www.usc.es/biogroup 